\title{
Metallothionein - overexpression as a highly significant prognostic factor in melanoma: a prospective study on 1270 patients
}

\author{
G Weinlich*,', K Eisendle', E Hassler', M Baltaci', PO Fritsch' and B Zelger' \\ 'Clinical Department of Dermatology and Venerology, Innsbruck Medical University, Anichstrasse 35, Innsbruck A-6020, Austria
}

\begin{abstract}
Metallothioneins (MT) are ubiquitous, intracellular small proteins with high affinity for heavy metal ions. In the last decades, it was shown that MT overexpression in a variety of cancers is associated with resistance to anticancer drugs and is combined with a poor prognosis. In this prospective study, we examined the role of MT overexpression in melanoma patients as a prognostic factor for progression and survival. Between 1993 and 2004, 3386 patients with primary cutaneous melanoma were investigated by using a monoclonal antibody against MT on routinely fixed, paraffin-embedded tissues. In all, 1270 patients could be followed up for further statistical analysis (Fisher's exact test, Mantel-Haenszel $\chi^{2}$ test, Kaplan-Meier curves). The MT data of disease-free interval and overall survival were compared univariately and multivariately in Cox regression analysis. Immunohistochemical overexpression of MT in tumour cells of patients with primary melanoma (310 of 1270; 24.4\%) was associated with a higher risk for progression ( 117 of 167; 70.1\%) and reduced survival (80 of I 10; 72.7\%) of the disease $(P<0.000$ I). Similarly, Kaplan-Meier curves gave highly significant disadvantages for the MT-positive group. Univariate analysis (relative risk 7.4; $95 \%$ confidence interval $(\mathrm{Cl}) 5.2-10.2 ; \mathrm{P}<0.000 \mathrm{I}$ for progression; relative risk 7.1; 95\% Cl 4.7-10.9; $P<0.000$ I for survival), as well as multivariate analysis with other prognostic markers resulted in MT overexpression as a highly significant and independent factor for prognosis in primary melanoma.
\end{abstract}

British Journal of Cancer (2006) 94, 835-84I. doi: I0.1038/sj.bjc.6603028 www.bjcancer.com

Published online 28 February 2006

(c) 2006 Cancer Research UK

Keywords: metallothionein; melanoma; prognostic factor

Melanoma is one of the most aggressive neoplasms in humans and its incidence is still increasing. As there is still no effective curative treatment in patients with disseminated melanoma, it is important to estimate the risk for progression in the individual patient, preferably at the time point of primary diagnosis. Breslow tumour thickness is still the best prognostic factor for this issue. Notwithstanding, everyone is aware of patients with thick melanoma, who never develop metastases, and patients with 'low-risk melanomas' (thinner than $1.0 \mathrm{~mm}$ ), who will show tumour progression in subsequent years. Therefore, additional factors reliably determining progression and survival would be of great benefit.

Metallothioneins (MT) are a group of ubiquitous, intracellular, low molecular weight proteins (approximately $6.5 \mathrm{kDa}$ ) with about $30 \%$ consisting of cysteine residues and no aromatic amino acids. They have a specific binding capacity for heavy metal ions of group II such as zinc, copper or cadmium (Nath et al, 1988; Miles et al, 2000; Nordberg and Nordberg, 2000). To date, four major isoforms have been identified in mammals; the specific functional roles of MT isoforms or molecular interaction are still not precisely known. As far as we know, MT are involved in many physiological and pathophysiological processes such as the intracellular storage, transport and metabolism of heavy metal ions; they regulate essential trace metal homeostasis and play a protective role in

*Correspondence: Dr G Weinlich; E-mail: georg.weinlich@uibk.ac.at Received 16 December 2005; revised 30 January 2006; accepted 31 January 2006; published online 28 February 2006 heavy metal detoxification reactions (Miles et al, 2000; Simpkins, 2000). They can protect cells against UV-/ionic radiation (Hansen et al, 1997; Hanada et al, 1998; Reeve et al, 2000) as well as cytotoxic alkylating agents including chemotherapeutics (Chin et al, 1993; Hishikawa et al, 1997; Okazaki et al, 1998; Sunada et al, 2005), modulate oxygen free radicals and nitric oxide and inhibit apoptosis (Tsangaris and Tzortzatou-Stathopoulou, 1998). The synthesis of MT is induced by group II heavy metal ions as well as by endogenous factors such as glucocorticoids, cytokines (interleukin (IL)-1 or IL-6, interferon $\gamma$ (IFN $\gamma$ ), tumour necrosis factor $\alpha$ $(\mathrm{TNF}-\alpha)$ ) or vitamin $\mathrm{D}_{3}$ (Karin et al, 1985; Karasawa et al, 1987; Schroeder and Cousins, 1990; Sato and Sasaki, 1992; Nishimura et al, 2000). There is also some evidence that inflammatory stressors (e.g. heat-shock proteins, reactive oxygen species, endotoxin, IL-1, IL-6) induce MT synthesis, which, subsequently, is strongly chemotactic for inflammatory cells, for example, $\mathrm{T}$ cells (Yin et al, 2005), and influences angiogenesis (Miyashita and Sato, 2005).

Although MT participate in the carcinogenic process, their use as a potential marker for tumour differentiation or cell proliferation, as well as a marker of poor prognosis remains controversial (Cherian et al, 2003; Theocharis et al, 2004). In the last decade, several reports disclosed MT overexpression as a useful prognostic factor for tumour progression and drug resistance in a variety of cancers such as ovarian cancer (Surowiak et al, 2005), renal cell carcinoma (Mitropoulos et al, 2005), breast cancer (Jin et al, 2004), non-small-cell lung carcinomas (Dziegiel et al, 2004), acute lymphoblastic leukaemia (Sauerbrey et al, 1994), pancreatic carcinoma (Ohshio et al, 1996) or carcinoma of the gallbladder 
The specimens were scored as negative if there was a complete (Shukla et al, 1998). Similar results could be found in smaller retrospective studies in melanoma and nonmelanoma skin cancers (Zelger et al, 1993, 1994; Rossen et al, 1997; Goldmann et al, 1998; Sugita et al, 2001). In some other tumours such as colorectal and bladder cancer, MT overexpression was not correlated with increased malignancy (Öfner et al, 1994; Jasani and Schmid, 1997).

In 2003, our department published the data of a prospective study on 520 melanoma patients, where we were able to show that MT overexpression is a significant and independent marker for poor prognosis and survival (Weinlich et al, 2003). In the present study, we present an update of this prospective cohort 11 years after initiation.

\section{MATERIALS AND METHODS}

\section{Patients}

This prospective study was started in 1993 at the Clinical Department of Dermatology and Venerology, Innsbruck Medical University, Austria. Up to the end of 2004, 3386 patients with a histological diagnosis of cutaneous melanoma were enrolled, and 1270 patients could be evaluated for further statistical analysis. Besides Breslow's tumour thickness and Clark's level, ulceration, location of the primary tumour, age and gender were added for statistical analysis. Measuring end points were the time when a progression (lymph node and/or distant metastasis) was detected and when the patients died due to widespread disease. In the vast majority of our patients (more than 90\%), a histopathological verification of the progression was possible by excision of metastases or biopsy of suspicious lesions before initiation of further therapy modalities.

\section{Histopathological analysis}

Formalin-fixed and paraffin-embedded tissues from melanoma patients were routinely stained with haematoxylin and eosin. For immunohistochemical investigations, sections of $4 \mu \mathrm{m}$ were mounted on chromgel-coated glass slides, deparaffinised in xylene, rehydrated in a graded series of alcohol and rinsed in Tris buffer. Endogenous peroxidase was blocked by means of sodium azide, glucose and glucose-oxidase. The primary monoclonal MT mouseIgG1 antibody E9 (clone E9; Dako, Denmark), which reacts with both human epitopes of MT I and II isoforms, was applied, followed by a peroxidase-conjugated rabbit-anti-mouse antibody. The enzyme reaction was developed in a freshly prepared solution containing 3-amino-9-ethylcarbazole and $0.01 \%$ hydrogen peroxide. Then, the sections were counterstained with haematoxylin, dehydrated, cleared in xylene and mounted with entellan (Evering et al, 1990; Jasani and Elmes, 1991). In those cases, where we had multiple blocks of tumour specimens, the immunohistochemical labelling was performed in all of them.

The stained sections were independently assessed by two independent dermatohistopathological observers by an eyeball estimate (EH and $\mathrm{MB}$ ) without prior knowledge of the clinical data. Generally, a good correlation and reproducibility was obtained by the two observers. In rare cases of disagreement $(<5 \%)$, both reporting colleges $(\mathrm{EH}+\mathrm{MB})$ sat together with the senior author (BZ), who has established this technique previously (Zelger et al, 1993; Zelger et al, 1994; Weinlich et al, 2003), discussed the findings and performed the final evaluation. Only tumour cells staining well above the background level (faint labelling was occasionally observed around strongly positive cells, most likely due to antigen diffusion) were considered to be positive. Reactivity of basal keratocytes, the proliferating epithelium of the follicular bulb and ductal epithelium of eccrine and apocrine glands served as a positive internal control. lack of MT-positive cells, and only a faint hue of reactivity compared with positive internal controls or only a minor component of up to $10 \%$ positive tumour cells. Reactivity of more than $10 \%$ was interpreted as MT overexpression. The limiting value of $10 \%$ was chosen to prevent false-positive results. On the one hand, the physiological proliferation rate of normal tissues as well as the reactivity of various forms of melanocytic naevi are usually smaller than our cutoff level; on the other hand, a counting of cells less than $10 \%$, although perhaps sufficient enough, would be more inexact to measure by an eyeball estimate. In most of the MT-positive cases, the MT monoclonal antibody diffusely labelled the majority of tumour cells (Figure 1).

\section{Statistical analysis}

The ascertained data were statistically analysed using an SPSS statistical software (SPSS for Windows, version 12.0; SPSS Inc., Chicago, IL, USA). The correlation between the immunohistochemical data (absence or presence of MT overexpression) was compared with the clinicopathological data (the occurrence or not of metastasis and/or death due to melanoma) using the two-tailed Fisher's exact test and the Mantel-Haenszel $\chi^{2}$ test. Kaplan-Meier curves were used to estimate the progression and survival (Kaplan and Meier, 1958). Odds ratios and 95\% confidence intervals (CIs) were calculated for all known prognostic factors for progression and survival using Cox regression analysis, assuming proportional hazards in a univariate as well as multivariate approach (Spiegel, 1990). A $P$-value of $<0.05$ was considered statistically significant in every statistical analysis.

\section{RESULTS}

Between 1993 and 2004, 3386 patients were recruited for this study; 1270 of them could be evaluated for statistical analysis. According to standard guidelines of the Austrian Society of Dermatology and Venerology, the majority of low-risk melanoma patients were followed up by their local dermatologist, but never had dermatological control for follow-up at our department, which was one of the criteria for inclusion into the statistical analysis. In addition, only patients with at least 3 months of observation could enter this study. So out of the 3386 recruited, 1226 patients had to be dropped, because they were lost for follow-up (observation $<3$ months). The majority of the lost patients had low-risk melanomas $<1.0 \mathrm{~mm}$ or in situ melanomas $(n=1167,95 \%)$. An additional 890 patients had to be dropped out for the statistical analysis (in situ melanomas). Within the rest of the group of 1270 statistically evaluable patients ( $>$ in situ, $\geqslant 3$ months, complete data set), males and females were nearly balanced (51\%/49\%), and the median age at the time of excision was 54 years (range 7-95 years). Breslow tumour thickness varied between $0.12 \mathrm{~mm}$ and a tumour thickness of $30 \mathrm{~mm}$ (median value $0.7 \mathrm{~mm}$, mean $1.3 \mathrm{~mm}$ ). Table 1 gives the characteristics of the 3386 patients included in the data set and of those 1270 eligible for further analysis.

In 11 years of recruitment (median observation time 32 months), 167 of 1270 patients (13.1\%) showed a progression of their disease, and the median time to progression was 18.0 months (mean value 26.0 months). In all, 110 of these patients $(8.7 \%)$ died because of the metastatic disease of melanoma. The median time between detection of the first metastasis to death was 9.0 months (mean 15.3 months), and the median time from primary diagnosis of melanoma to death was 26.5 months (mean 35.1 months). None of our patients with a tumour thickness $<0.5 \mathrm{~mm}$ developed metastases.

The majority of patients who showed progression, that is, 117 of $167(70.1 \%)$, and from those who died due to metastasis, that is, 80 of $110(72.7 \%)$, showed an MT-overexpression of their primary 

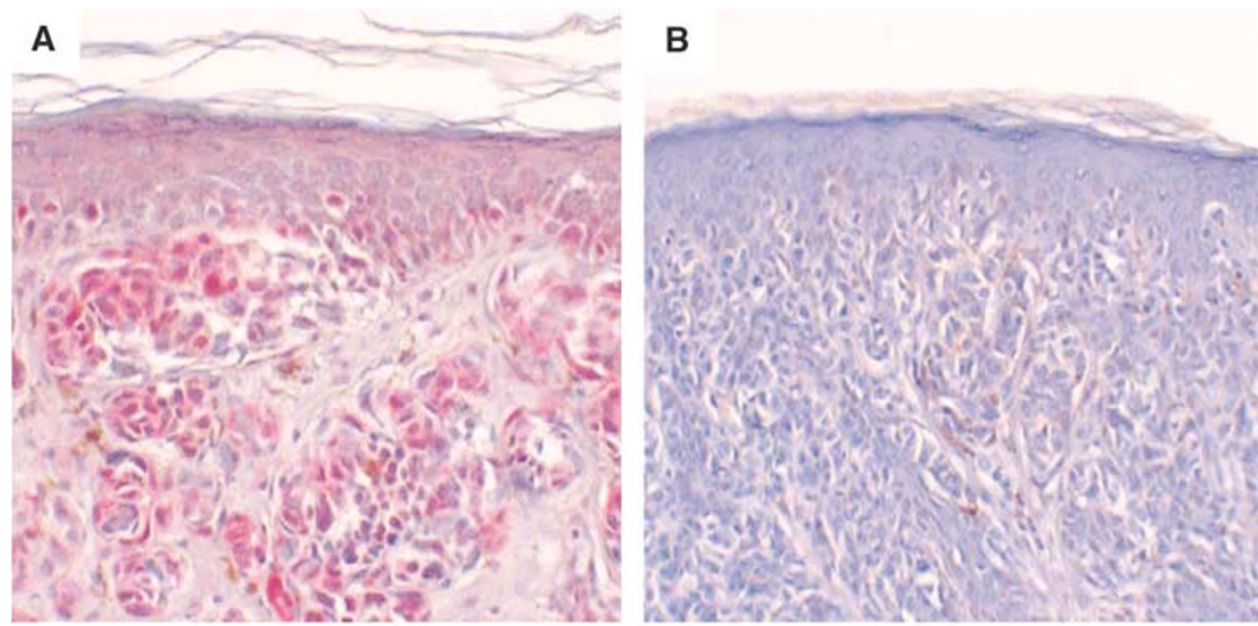

C

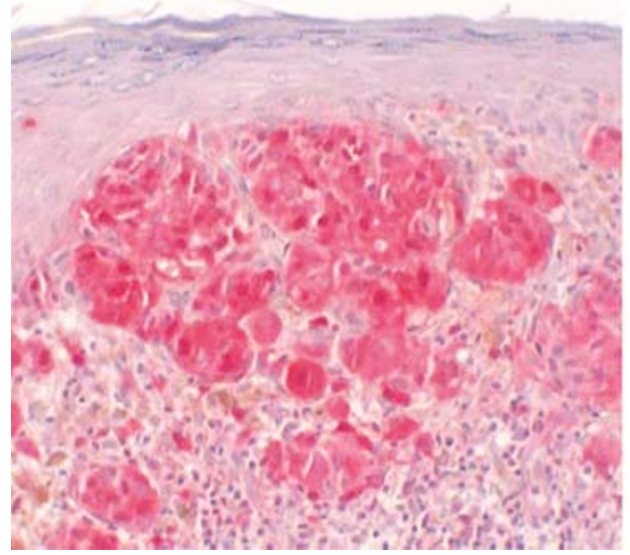

D

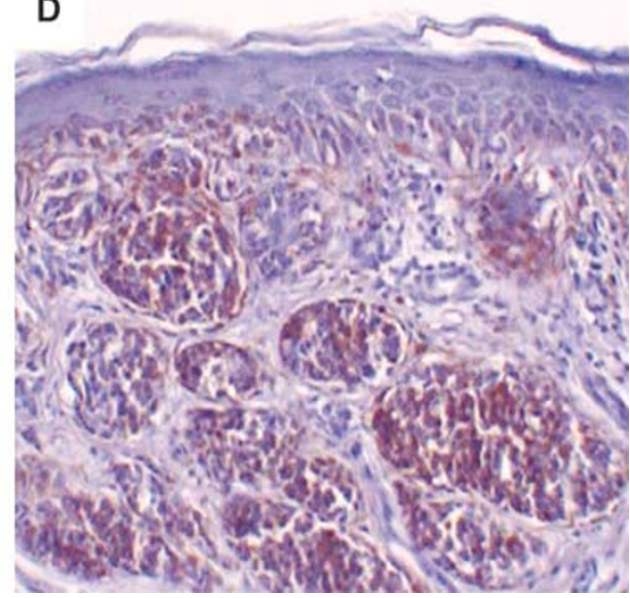

Figure I Metallothionein (MT)-positive $(\mathbf{A}+\mathbf{C})$ and MT-negative $(\mathbf{B}+\mathbf{D})$ melanomas with comparable tumour thickness $(\mathbf{A}+\mathbf{B} 0.6 \mathrm{~mm} C L \mathrm{III}, \mathbf{C}+\mathbf{D}$ $1.0 \mathrm{~mm} C L \mathrm{IV}$ ). The red colour of ACE (in $\mathbf{A}+\mathbf{C}$ ) indicates positivity, the brown colour (in $\mathbf{D}$ ) represents melanin.

melanoma ( $P<0.001, \chi^{2}$ test; Fisher's exact test) (Table 2). Even in patients with low-risk melanomas $<1.0 \mathrm{~mm}$ (846 of 1270), the majority of those with progression, that is, 21 of $32(65.6 \%$, $\left.\chi^{2}=63.9 ; \mathrm{df}=1 ; P<0.001\right)$, and those who died, that is, 11 of 15 (73.3\%, $\left.\chi^{2}=39.0 ; \mathrm{df}=1 ; P<0.001\right)$, showed statistically significant MT overexpression in their primary melanoma.

Figure 2 illustrates the progression and survival of melanoma patients over a time period of 150 months estimated by the Kaplan-Meier method. A total of $55.9 \%$ of the MT-positive group, but only $10.9 \%$ of the MT-negative group developed metastasis after 10 years of observation $(P<0.0001) ; 44.1 \%$ of MTpositive patients died within a period of 120 months due to progression of melanoma, but only $6.8 \%$ of patients in the MTnegative group $(P<0.0001)$. According to the tumour node metastasis (TNM) classification of the American Joint Committee on Cancer 2001, we subdivided our patients into four groups ( $<1.0 \mathrm{~mm}, 1.01-2.0 \mathrm{~mm}, 2.01-4.0 \mathrm{~mm},>4.01 \mathrm{~mm}$ ) with similar results. Even in the group of low-risk melanomas thinner than $1.0 \mathrm{~mm}$, the prognosis for the MT-positive group was worse in comparison with the MT-negative group. Figure 3 illustrates the Kaplan-Meier curves for the progress-free interval; analogous data for survival are not shown.

As the percentage of MT-positive melanomas was increasing with higher Clark level and Breslow tumour thickness, we tried to find out in a next step if MT overexpression is an independent prognostic marker or just a parameter correlated with increasing invasion level or tumour thickness. First, in a univariate Cox proportional hazard model for disease progression, we found a high significance of MT overexpression with an expected risk of 7.4 (95\% CI 5.3-10.2). Metallothionein overexpression as well as all groups of Breslow tumour thickness had $P$-values $<0.001$ in the univariate analysis (Table 3 ). The patient's data were also calculated according to survival with similar results (expected risk 7.2, 95\% CI $4.7-10.9 ; P<0.001$ )

Then, we adjusted the data of our patients according to other prognostic factors such as Breslow tumour thickness, Clark level, ulceration, tumour localisation, median age, gender and MT overexpression in a multivariate Cox regression analysis to prove the independence of these factors. The strongest significant parameters for progression were tumour thickness and MT overexpression; only Clark level $\mathrm{V}$ reached a significance of $P<0.05$, and ulceration was not significant in our cohort (Table 4). In the Cox regression model for survival, we found similar results with two highly significant and independent parameters: MT overexpression and Breslow tumour thickness.

For a further calculation, we adapted the regression analysis with Breslow tumour thickness and age as continuous variables (table not shown). In this model, tumour thickness (expected risk $1.13 ; 95 \%$ CI $1.1-1.2 ; P<0.001)$ and again MT overexpression (expected risk 4.2; 95\% CI 2.9-5.9; $P<0.001$ ) showed significant results; Clark level IV (expected risk 5.9, 95\% CI 1.8-19.3; $P=0.003$ ), Clark level V (expected risk 11.4, 95\% CI 3.2-40.1; $P<0.001$ ), ulceration (expected risk $1.5 ; 95 \%$ CI $1.0-2.2 ; P=0.035$ ) as well as age (expected risk 1.0, 95\% CI $1.01-1.03 ; P=0.001$ ) were significant too. Analogous results could be found when we calculated the same data in the analysis for survival, with only a 
small difference; the localisation also reached a $P$-value $<0.02$ (expected risk 1.7, 95\% CI 1.1-2.6).

\section{DISCUSSION}

Although there is still no effective treatment for disseminated melanoma (stage IV), it is of great interest to estimate the risk for a

Table I Characteristics of melanoma patients 1993-2004

\begin{tabular}{|c|c|c|}
\hline $\begin{array}{l}\text { Number of } \\
\text { patients }\end{array}$ & $\begin{array}{c}\quad n=3386 \\
\text { (all patients } \\
\text { recruited I993- } \\
\text { 2004) }\end{array}$ & $\begin{array}{c}\mathbf{n}=1270 \\
(>\text { in situ, } \geqslant 3 \\
\text { months } \\
\text { observation) }\end{array}$ \\
\hline \multicolumn{3}{|c|}{ Observation time (months) } \\
\hline Range & $0-143$ & $3-143$ \\
\hline Mean & 26.3 & 42.5 \\
\hline Median & 13.0 & 32.0 \\
\hline \multicolumn{3}{|l|}{ Age (years) } \\
\hline Range & $5-100$ & $7-95$ \\
\hline Mean & 55.0 & 53.2 \\
\hline Median & 57.0 & 54.0 \\
\hline \multicolumn{3}{|l|}{ Sex } \\
\hline Male & 1589 (46.9\%) & $649(51.1 \%)$ \\
\hline Female & $1797(53.1 \%)$ & $621(48.9 \%)$ \\
\hline \multicolumn{3}{|l|}{ Localisation } \\
\hline TANS & $2228(65.8 \%)$ & 772 (60.8\%) \\
\hline Not TANS & $1158(34.2 \%)$ & $498(39.2 \%)$ \\
\hline \multicolumn{3}{|l|}{ Ulceration } \\
\hline Present & $157(4.6 \%)$ & $123(9.7 \%)$ \\
\hline Absent & $3229(95.4 \%)$ & I 147 (90.3\%) \\
\hline \multicolumn{3}{|c|}{ Tumour thickness (mm) } \\
\hline In situ & $1613(47.6 \%)$ & \\
\hline$<1.0$ & $129 \mid(38.1 \%)$ & $846(66.6 \%)$ \\
\hline $1.01-2.0$ & $263(7.8 \%)$ & $236(18.6 \%)$ \\
\hline $2.01-4.0$ & $124(3.7 \%)$ & $104(8.2 \%)$ \\
\hline$>4.01$ & $95(2.8 \%)$ & $84(6.6 \%)$ \\
\hline \multicolumn{3}{|l|}{ Invasion level } \\
\hline CL I & $1613(47.6 \%)$ & \\
\hline$C L \|$ & $257(7.6 \%)$ & $176(13.9 \%)$ \\
\hline$C L \|$ & $1084(32.0 \%)$ & 736 (71.8\%) \\
\hline CL IV & $376(11.1 \%)$ & $313(24.6 \%)$ \\
\hline$C L \vee$ & $56(1.7 \%)$ & $45(3.5 \%)$ \\
\hline
\end{tabular}

$\mathrm{CL}=$ Clark level; $\mathrm{TANS}=$ thorax, upper arm, neck, scalp.
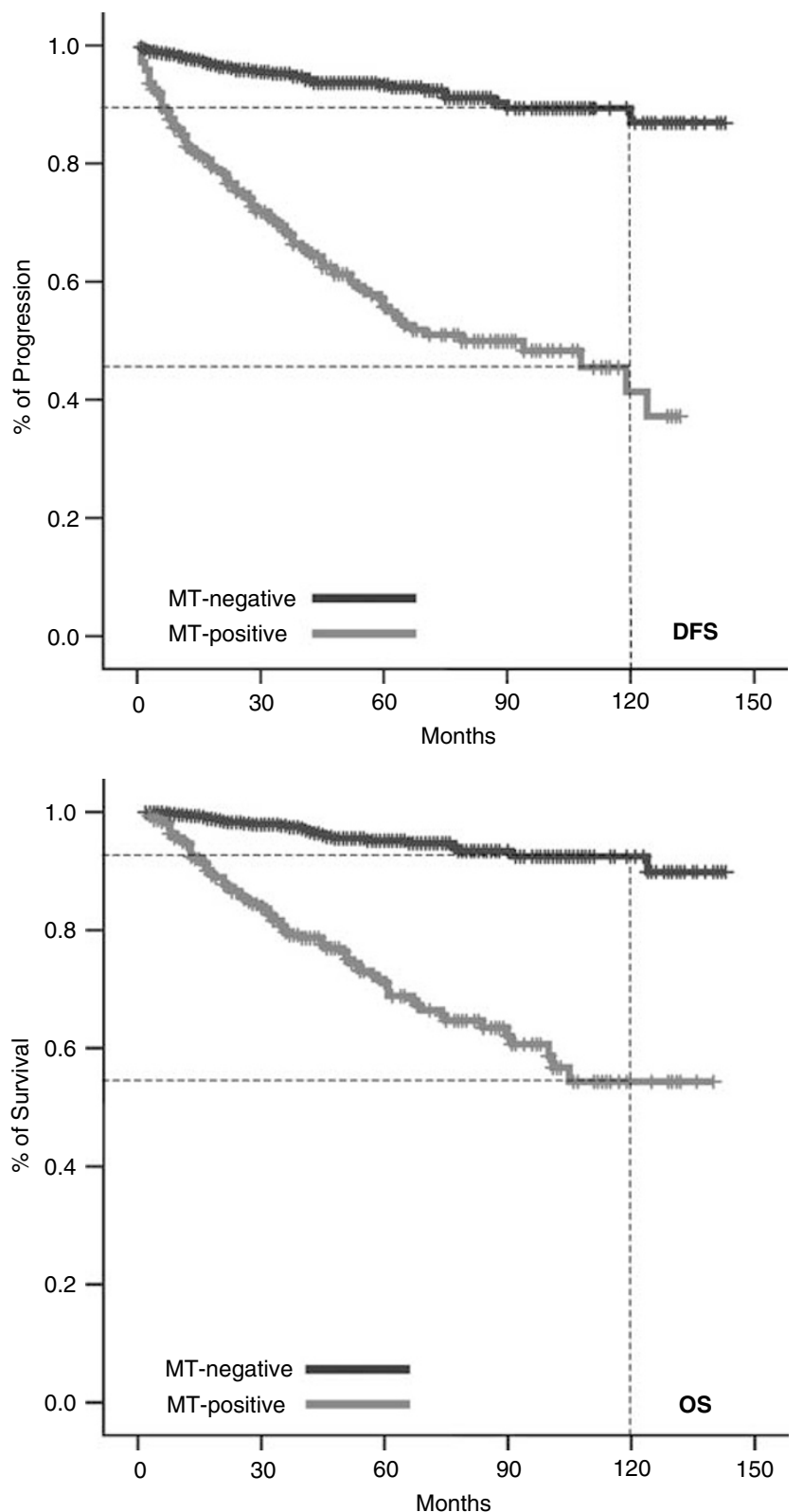

Figure 2 Kaplan-Meier estimates for progression and survival in melanoma patients.

Table 2 Characteristics of MT overexpression in primary melanoma

\begin{tabular}{|c|c|c|c|c|c|}
\hline $\begin{array}{l}\text { Number of melanoma } \\
\text { Tumour thickness }(\mathrm{mm})\end{array}$ & 1270 & \multicolumn{2}{|c|}{ MT-positive } & \multicolumn{2}{|c|}{ MT-negative } \\
\hline $2.01-4.0$ & 104 & 53 & $51.00 \%$ & 51 & $49.00 \%$ \\
\hline$>4.01$ & 84 & 48 & $57.10 \%$ & 36 & $42.90 \%$ \\
\hline $\begin{array}{l}\text { Death }(n=110,8.7 \%) \\
\left(\chi^{2}=\mid 52.4, d f=1, P<0.001\right)\end{array}$ & & 80 & $72.70 \%$ & 30 & $27.30 \%$ \\
\hline
\end{tabular}

MT = metallothionein. 

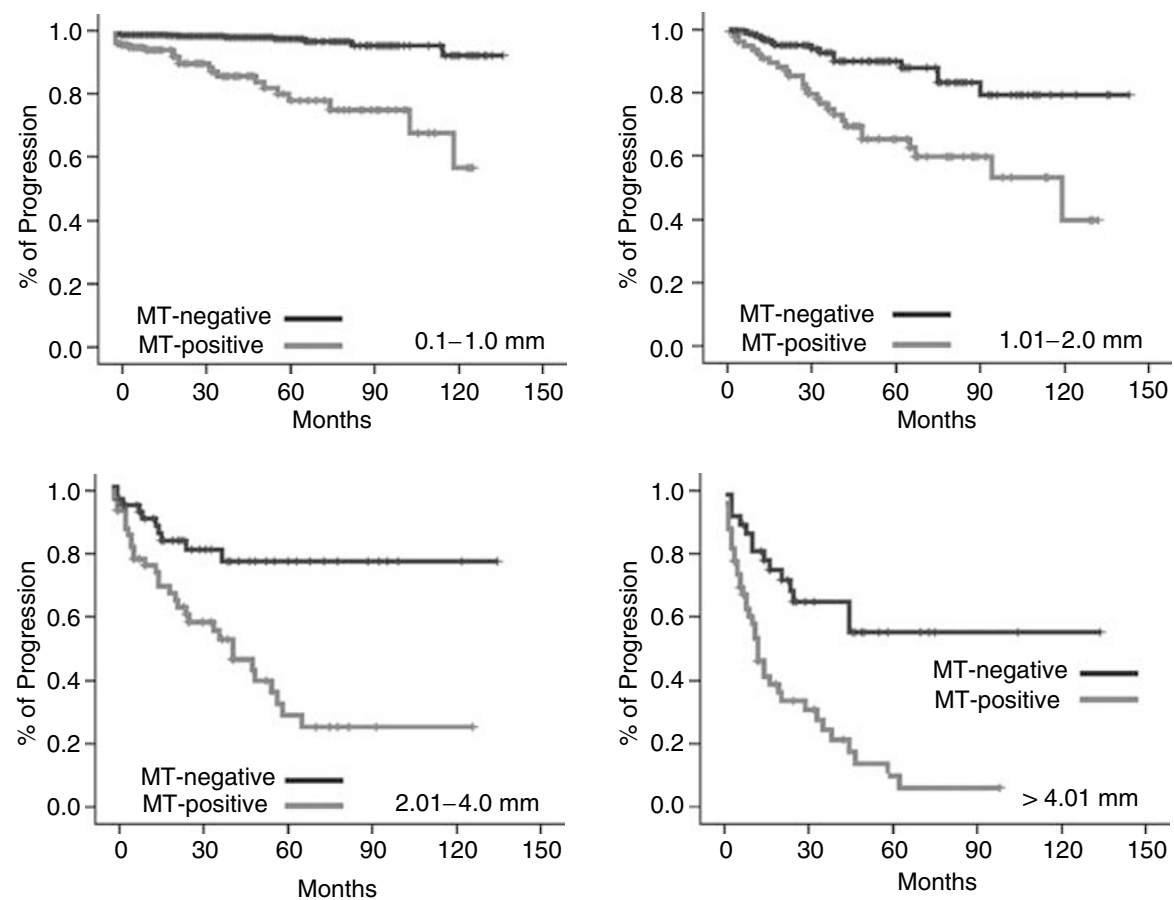

Figure 3 Kaplan-Meier curves for progression in melanoma patients in the different groups of Breslow tumour thickness.

Table 3 Univariate Cox proportional hazard model for disease progression and survival (tumour thickness/MT overexpression)

\begin{tabular}{|c|c|c|c|c|c|c|}
\hline$n=1270$ & \multicolumn{3}{|c|}{ Progression } & \multicolumn{3}{|c|}{ Survival } \\
\hline \multicolumn{7}{|c|}{ Tumour thickness (mm) } \\
\hline$<1.0$ & । & & & । & & \\
\hline $1.01-2.0$ & 4.24 & $2.68-6.72$ & $<0.001$ & 5.44 & $2.9-10.19$ & $<0.001$ \\
\hline
\end{tabular}

$\mathrm{Cl}=$ confidence interval; $\mathrm{CL}=$ Clark level; $\mathrm{MT}=$ metallothionein.

possible progression as early as possible, at the time point of the primary diagnosis of melanoma. Up to now, Breslow tumour thickness is still the best prognostic marker in primary melanoma. Over the preceding years, a wide variety of different prognostic factors have been investigated: Clark level, tumour stage, growth phase, ulceration, mitotic counts or tumour-infiltrating lymphocytes and many others. Most of these other prognostic markers often derive their predictive value because of a direct or secondary correlation with tumour thickness.

In this prospective study on 1270 melanoma patients with a long time of follow-up, our statistical analysis was able to document that MT overexpression is a potent, highly significant and tumour thickness-independent factor, which helps to assess and calculate the risk for subsequent progression. This could be shown by several statistical methods like $\chi^{2}$ test, Fisher's exact test, Kaplan-Meier curves, as well as uniand multivariate Cox regression analysis. Our data are highly significant in all used test systems, although 2116 out of 3386 initially included patients had to be dropped out, $95 \%$ of them with melanomas $<1.0 \mathrm{~mm}$, in situ melanomas or because of too short a time of observation, due to our strict inclusion criteria.
Our results can be interpreted from different aspects: on the one hand, MT-negative melanoma thinner than $1.0 \mathrm{~mm}$ practically never cause any further problems. There were only three cases of metastasis from an MT-negative melanoma thinner than $1.0 \mathrm{~mm}$ (three out of 1067 MT-negative cases, $0.28 \%$ ); two of them had distinct histological signs of regression. In our cohort, none of the patients with tumours $<0.5 \mathrm{~mm}$ (591 patients with 54/9.1\% MT positive) developed metastasis in the subsequent years. This may assure such patients of their good long-term outcome. So it should be deliberated if MT-negative patients with melanomas thinner than $1.0 \mathrm{~mm}$ could be controlled more generously without ultrasound- or X-ray-staging examinations. On the other hand, MT-positive melanoma thinner than $1.0 \mathrm{~mm}$ are at a higher risk of developing metastasis and succumbing to their neoplastic disease. In our study population, $5.3 \%$ of the patients in this 'low-risk' group (nine out of $170 \mathrm{MT}$-positive melanomas $<1.0 \mathrm{~mm}$ ) showed a progression of their disease; their relative risk is roughly comparable to MT-negative melanoma with a thickness of $2.1-$ $4 \mathrm{~mm}$. This may be used to more carefully follow up these patients and/or probably even serve as a tool to indicate and perform sentinel lymph node biopsy. Moreover, this group of patients could probably profit from adjuvant treatment. 
Table 4 Multivariate Cox regression analysis results for disease progression and survival in melanoma patients

\begin{tabular}{|c|c|c|c|c|c|c|}
\hline \multirow[b]{2}{*}{$n=1270$} & \multicolumn{3}{|c|}{ Progression } & \multicolumn{3}{|c|}{ Survival } \\
\hline & Relative risk & Cl $95 \%$ & $P$-value & Relative risk & Cl $95 \%$ & $P$-value \\
\hline$<1.0$ & I & & & I & & \\
\hline $1.01-2.0$ & 1.97 & $|| 4-3.4 \mid$. & 0.015 & 2.55 & $1.24-5.25$ & 0.011 \\
\hline $2.01-4.0$ & 3.46 & $1.91-6.28$ & $<0.001$ & 3.64 & $1.63-8.13$ & 0.002 \\
\hline \multicolumn{7}{|l|}{ Clark level } \\
\hline$C L \|$ & । & & & । & & \\
\hline$C L \|$ & 2.11 & $0.64-6.95$ & 0.22 & 3.09 & $0.40-23.57$ & 0.277 \\
\hline CL IV & 3.29 & $0.94-11.50$ & 0.062 & 4.94 & $0.61-39.79$ & 0.133 \\
\hline$C L \vee$ & 5.75 & $1.51-21.90$ & 0.01 & 8.36 & $0.98-71.55$ & 0.053 \\
\hline \multicolumn{7}{|l|}{ Ulceration } \\
\hline \multicolumn{7}{|l|}{ Gender } \\
\hline Female & 0.84 & $0.60-1.16$ & 0.279 & 1.04 & $0.69-1.54$ & 0.862 \\
\hline \multicolumn{7}{|l|}{ Location } \\
\hline TANS & 0.88 & $0.64-1.22$ & 0.443 & 1.48 & $0.99-2.22$ & 0.059 \\
\hline
\end{tabular}

$\mathrm{Cl}=$ confidence interval; $\mathrm{CL}=$ Clark level; $\mathrm{MT}=$ metallothionein; TANS = thorax, upper arm, neck, scalp.

Metallothionein overexpression probably has an additional value. In stage IV melanoma patients, anticancer drugs, as well as irradiation therapy, are known to often show only a humbled rate of clinical responses. These therapeutic failures may partially be related to an enhanced MT overexpression in tumour cells, although the involvement of MT in conferring resistance to chemotherapeutics still remains under discussion (Chin et al, 1993; Hishikawa et al, 1997; Okazaki et al, 1998; Cherian et al, 2003). As a variety of endogenous factors (e.g. glucocorticosteroids, ILs, IFN $\gamma$, TNF- $\alpha$ ) are involved in the induction of the synthesis of intracellular MT, one may suggest that this may lead to an overprotection of tumour cells against apoptosis, and, on the other hand, supporting the metastatic behaviour of the tumour (Karin et al, 1985; Karasawa et al, 1987; Nath et al, 1988; Schroeder and Cousins, 1990; Sato and Sasaki, 1992; Tsangaris and TzortzatouStathopoulou, 1998; Miles et al, 2000; Nishimura et al, 2000).

In summary, our data confirm previous results of retrospective and much smaller studies in melanoma, outlining that MT overexpression is a useful and elegant tool for prognostication (Zelger et al, 1993; Goldmann et al, 1998; Sugita et al, 2001). This marker is highly significant and independent of tumour thickness and already predictive in low-risk melanomas thinner than $1.0 \mathrm{~mm}$. These investigations by immunohistochemical labelling on archival paraffin material are easy to assess and perform in routine pathology and dermatopathology laboratories and the costs are limited.

\section{ACKNOWLEDGEMENTS}

We thank Dr P Puffer, private pathologist in Innsbruck, for allocating a great number of tumour samples for the MT investigations. We are also heavily indebted to Dr V Mayr and L Richardsen for their help in the data collection and to B Moser and $\mathrm{N}$ Greier for their technical assistance.

\section{REFERENCES}

Cherian MG, Jayasurya A, Bay BH (2003) Metallothioneins in human tumors and potential roles in carcinogenesis. Mutat Res 533: 201-209; doi: 10.1016/j.mrfmmm.2003.07.013

Chin JL, Banerjee D, Kadhim SA, Kontozoglou TE, Chauvin PJ, Cherian MG (1993) Metallothionein in testicular germ cell tumours and drug resistance. Clinical correlation. Cancer 72: 3029-3035; doi: 10.1080/ 10623320500227101

Dziegiel P, Jelen M, Muszczynska B, Maciejczyk A, Szulc A, PodhorskaOkolow M, Cegielski M, Zabel M (2004) Role of metallothionein expression in non-small cell lung carcinomas. Rocz Akad Med Bialymst 49: 43-45

Evering WE, Haywood S, Elmes ME, Jasani B, Trafford J (1990) Histochemical and immunocytochemical evaluation of copper and metallothionein in the liver and kidney of copper-loaded rats. J Pathol 160: 305-312; doi: 10.1002/path.1711600406
Goldmann T, Ribbert D, Suter L, Brode M, Otto F (1998) Tumour characteristics involved in the metastatic behaviour as an improvement in primary cutaneous melanoma prognostics. J Exp Clin Cancer Res 17: $483-489$

Hanada K, Sawamura D, Tamai K, Baba T, Hashimoto I, Muramatsu T, Miura N, Naganuma A (1998) Novel function of metallothionein in photoprotection: metallothionein-null mouse exhibits reduced tolerance against ultraviolet B injury in the skin. J Invest Dermatol 111: 582-585

Hansen C, Ablett E, Green A, Sturm RA, Dunn IS, Fairlie DP, West ML, Parsons PG (1997) Biphasic response of the metallothionein promoter to ultraviolet radiation in human melanoma cells. Photochem Photobiol 65: $550-555$

Hishikawa Y, Abe S, Kinugasa S, Yoshimura H, Monden N, Igarashi M, Tachibana M, Nagasue N (1997) Overexpression of metallothionein 
correlates with chemoresistance to cisplatin and prognosis in oesophageal cancer. Oncology 54: $342-347$

Jasani B, Elmes ME (1991) Immunohistochemical detection of metallothionein. Methods Enzymol 205: 95-107

Jasani B, Schmid KW (1997) Significance of metallothionein overexpression in human tumours. Histopathology 31: 211-214

Jin R, Huang J, Tan PH, Bay BH (2004) Clinicopathological significance of metallothioneins in breast cancer. Pathol Oncol Res 10: 74-79; doi: 10.1186/1471-2172-6-21, doi: PAOR.2004.10.2.0074

Kaplan EL, Meier P (1958) Nonparametric estimations from incomplete observations. J Am Stat Assoc 53: 457-481

Karasawa M, Hosoi J, Hashiba H, Nose K, Tohyama C, Abe E, Suda T, Kuroki T (1987) Regulation of metallothionein gene expression by 1 alpha,25-dihydroxyvitamin D3 in cultured cells and in mice. Proc Natl Acad Sci 84: $8810-8813$

Karin M, Imbra RJ, Heguy A, Wong G (1985) Interleukin 1 regulates human metallothionein gene expression. Mol Cell Biol 5: 2866-2869

Miles AT, Hawksworth GM, Beattie JH, Rodilla V (2000) Induction, regulation, degradation, and biological significance of mammalian metallothioneins. Crit Rev Biochem Mol Biol 35: 35-70

Mitropoulos D, Kyroudi-Voulgari A, Theocharis S, Serafetinides E, Moraitis E, Zervas A, Kittas C (2005) Prognostic significance of metallothionein expression in renal cell carcinoma. World J Surg Oncol 3: 5; doi: 10.1186/ 1477-7819-3-5

Miyashita H, Sato Y (2005) Metallothionein 1 is a downstream target of vascular endothelial zinc finger 1 (VEZF1) in endothelial cells and participates in the regulation of angiogenesis. Endothelium 12(4): $163-$ 170; doi: 10.1080/10623320500227101

Nath R, Kambadur R, Gulati S, Paliwal VK, Sharma M (1988) Molecular aspects, physiological functions, and clinical significance of metallothioneins. Crit Rev Food Sci Nutr 27: $41-85$

Nishimura N, Reeve VE, Nishimura H, Satoh M, Tohyama C (2000) Cutaneous metallothionein induction by ultraviolet $\mathrm{B}$ irradiation in interleukin-6 null mice. J Invest Dermatol 114: 343-348

Nordberg M, Nordberg GF (2000) Toxicological aspects of metallothionein. Cell Mol Biol 46: $451-463$

Öfner D, Maier H, Riedmann B, Bammer T, Rumer A, Winde G, Bocker W, Jasani B, Schmid KW (1994) Immunohistochemical metallothionein expression in colorectal adenocarcinoma: correlation with tumour stage and patient survival. Virchows Arch 425: $491-497$

Ohshio G, Imamura T, Okada N, Wang ZH, Yamaki K, Kyogoku T, Suwa H, Yamabe H, Imamura M (1996) Immunohistochemical study of metallothionein in pancreatic carcinomas. J Cancer Res Clin Oncol 122: $351-355$

Okazaki Y, Miura N, Satoh M, Imura N, Naganuma A (1998) Metallothionein-mediated resistance to multiple drugs can be induced by several anticancer drugs in mice. Biochem Biophys Res Commun 245: 815-818

Reeve VE, Nishimura N, Bosnic M, Michalska AE, Choo KH (2000) Lack of metallothionein-I and -II exacerbates the immunosuppressive effect of ultraviolet B radiation and cis-urocanic acid in mice. Immunology 100: $399-404$
Rossen K, Haerslev T, Hou-Jensen K, Jacobsen GK (1997) Metallothionein expression in basaloid proliferations overlying dermatofibromas and in basal cell carcinomas. Br J Dermatol 136: 30-34

Sato M, Sasaki M (1992) Tissue-specific induction of metallothionein synthesis by tumour necrosis factor $\alpha$. Res Commun Chem Pathol Pharmacol 75: $159-172$

Sauerbrey A, Zintl F, Volm M (1994) Expression of metallothionein in initial and relapsed childhood acute lymphoblastic leukemia. Ann Hematol 69: $111-115$

Schroeder JJ, Cousins RJ (1990) Interleukin-6 regulates metallothionein gene expression and zinc metabolism in hepatocyte monolayer cultures. Proc Natl Acad Sci 87: 3137-3141

Shukla VK, Aryya NC, Pitale A, Pandey M, Dixit VK, Reddy CD, Gautam A (1998) Metallothionein expression in carcinoma of the gallbladder. Histopathology 33: $154-157$

Simpkins CO (2000) Metallothionein in human disease. Cell mol Biol 46: $465-488$

Spiegel MR (1990) Statistik (2nd edn). Hamburg: McGraw-Hill Book Company

Sugita K, Yamamoto O, Asahi M (2001) Immunohistochemical analysis of metallothionein expression in malignant melanoma in Japanese patients. Am J Dermatopathol 23: 29-35

Sunada F, Itabashi M, Ohkura H, Okumura T (2005) p53 negativity, CDC25B positivity, and metallothionein negativity are predictors of a response of esophageal squamous cell carcinoma to chemoradiotherapy. World J Gastroenterol 11: 5696-5700

Surowiak P, Materna V, Kaplenko I, Spaczynski M, Dietel M, Lage H, Zabel M (2005) Augmented expression of metallothionein and glutathione $S$ transferase pi as unfavourable prognostic factors in cisplatin-treated ovarian cancer patients. Virchows Arch 447: 626-633; doi: 10.1007/ s00428-005-1228-0

Theocharis SE, Margeli AP, Klijanienko JT, Kouraklis GP (2004) Metallothionein expression in human neoplasia. Histopathology 45: 103-118; doi: 10.1111/j.1365-2559.2004.01922.x

Tsangaris GT, Tzortzatou-Stathopoulou F (1998) Metallothionein expression prevents apoptosis: a study with antisense phosphorothioate oligodeoxynucleotides in a human $\mathrm{T}$ cell line. Anticancer Res 18: $2423-2434$

Weinlich G, Bitterlich W, Mayr V, Fritsch PO, Zelger B (2003) Metallothionein-overexpression as a prognostic factor for progression and survival in melanoma. A prospective study on 520 patients. $\mathrm{Br} J$ Dermatol 149: $535-541$

Yin X, Knecht DA, Lynes MA (2005) Metallothionein mediates leukocyte chemotaxis. BMC Immunol 6: 21 doi:10.1186/1471-2172-6-21

Zelger B, Hittmair A, Schir M, Öfner C, Öfner D, Fritsch PO, Bocker W, Jasani B, Schmid KW (1993) Immunohistochemically demonstrated metallothionein expression in malignant melanoma. Histopathology 23: $257-263$

Zelger B, Sidoroff A, Höpfl R, Öfner D, Jasani B, Schmid KW (1994) Metallothionein expression in nonmelanoma skin cancer. An immunohistochemical study. Appl Immunohistochem 2: 254-260 